\title{
OR23-3 Oral session
}

\section{Semi-synthetic sapogenin exerts neuroprotective effects by skewing the brain ischemia reperfusion transcriptome towards inflammatory resolution}

\author{
García-Pupo $L^{1}$, Sánchez $\mathrm{Jr}^{1}$, Ratman $\mathrm{D}^{2}$, Pérez-Novo $\mathrm{C}^{3}$, Declerck $\mathrm{K}^{3}$, De Bosscher $\mathrm{K}^{2}$, \\ Markakis $\mathrm{Mn}^{4}$, Beemster $\mathrm{G}^{4}$, Zaldo $\mathrm{A}^{5}$, Nuñez Figueredo $\mathrm{Y}^{1}$, Delgado-Hernández $\mathrm{R}^{1}$, Vanden \\ Berghe $\mathrm{W}^{3}$
}

${ }^{I}$ Centro de Investigación y Desarrollo de Medicamentos (CIDEM), BioCubaFarma, Cuba, ${ }^{2}$ Receptor Research Laboratories, Nuclear Receptor Lab, Medical Biotechnology Center, VIB, Department of Biochemistry, Ghent University, Belgium, ${ }^{3}$ Proteinscience, Proteomics and Epigenetic Signaling, Department of Biomedical Sciences, University of Antwerp, Belgium, ${ }^{4}$ Integrated Molecular Plant Physiology Research (IMPRES), Department of Biology, University of Antwerp, Campus Groenenborger, Belgium, ${ }^{5}$ Centro de Estudios de Productos Naturales, Facultad de Quimica, Universidad de la Habana, Zapata s/n entre G y Carlitos Aguirre, Vedado, Cuba

Stroke represents one of the first causes of mortality and morbidity worldwide. We evaluated the therapeutic potential of a novel semi-synthetic spirosteroid sapogenin derivative "S15" in a transient middle cerebral artery occlusion (tMCAO) focal ischemia model in rat. S15-treated rats had significantly reduced infarct volumes and improved neurological functions at $24 \mathrm{~h}$ post-reperfusion, compared with ischemia. Corresponding gene expression changes in brain were characterized by mRNA sequencing and qPCR approaches. Next, we applied geneset, pathway and transcription factor motif enrichment analysis to identify relevant signaling networks responsible for neuronal damage upon ischemiareperfusion or neuroprotection upon pretreatment with S15. As expected, ischemia-reperfusion brain damage strongly modulates transcriptional programs associated with immune responses, increased differentiation of immune cells as well as reduced (cat)ion transport and synaptic activity. Interestingly, S15-dependent neuroprotection regulates inflammationassociated genes involved in phagosome specific resolution of tissue damage, chemotaxis and anti-inflammatory alternative activation of microglia. Altogether our transcriptome wide RNA sequencing and integrated pathway analysis provides new clues in the neuroprotective properties of a novel spirosteroid S15 or neuronal damage in rat brains subjected to ischemia, which opens new perspectives for successful treatment of stroke. 